agglutinating and non-agglutinating antibodies to Salm. pullorum in hen's serum. 'The results of some of these experiments are shown in the accompanying table. By mixing a suitable concentration of trypsin with serum and incubating at $37^{\circ} \mathrm{C}$. for one hour at a $p \mathbf{H}$ of $8 \cdot 5$, it was possible to reduce and even destroy all demonstrable agglutinins without affecting the titres of non-agglutinating antibodies.

Details of experiments on the transfer of antibodies from the hen to the chick via the egg and the relationship between agglutinating and non-agglutinating antibodies will be published elsewhere.

I am much indebted to the Scientific Director of the Animal Health Trust and to the Director of the Trust's Poultry Research Station for their kindness in releasing me from my routine duties to undertake this work in Cambridge.

Department of Animal Pathology,
Cambridge.

\section{A. Buxton}

\section{Cambridge.}

June 15 .

${ }^{1}$ Morgan, W. T. J., and Schutze, H., Brit. J. Exp. Path., 27, 286 (1946).

'Needham, J., "Biochemistry and Morphogenesis" (Univ. Press, Cambridge, 1942)

${ }^{s}$ Marza, V. D., and Marza, E. V., Quart. J. Micro. Sci., 78, 133 (1935).

-Rosenheim, A. H., Biochem. J., 31, 54 (1937).

\section{Glucose and Lysogenesis in Bacillus megatherium}

CeLLS of Bacillus megatherium strain $1 \cdot 0$ can carry on metabolic activity, including multiplication, simultaneously with virus formation, for an infinite time; this balance between the cells and their virus is called lysogenesis. Evidence that lysogenic Bac. megatierium strain 1.0 can return to the normal uninfected state on a glucose nutrient medium was presented by Ehrlich and Watson ${ }^{1}$. Further study of this phenomenon showed that other sources of carbon, such as fructose, maltose, sucrose, glycerol, pyruvate and succinate in the basal medium all cause recovery from the lysogenic state. In postulating an explanation for this behaviour, it was thought that the virus and the source of carbon might compete for organic phosphate and that the virus was the weaker competitor. The work of Kozloff and Putnam suggested such a hypothesis ${ }^{2}$. However, initial studies showed that this hypothesis could not explain the effect of glucose on lysogenic Bac. megatherium strain 1.0.

Glucose in alkaline nutrient agar at $p \mathrm{H} 8.0$ was found to inhibit the growth of the lysogenic strain, whereas the uninfected parent strain was not inhibited. Of other sources of carbon that were added to the alkaline medium, only glucose-6-phosphate had an inhibitory effect on growth of the lysogenic strain. Fructose, fructose-6-phosphate, hexose diphosphate, $\alpha$-glycerophosphate and glycerol did not inhibit growth. Evidence that at least some of these intermediates of glycolysis can be utilized rests in part on the fact that resting-cell suspensions oxidized hexose diphosphate, glucose-6-phosphate, fructose-6phosphate and phosphoglycerate. Also, $0.01 \mathrm{M}$ sodium fluoride prevented the formation of lactic acid from glucose by resting-cell suspensions of uninfected Bac. megatherium.

These results suggest the following explanation for the effect of glucose. When glucose is present in a medium that contains a full complement of organic nitrogen compounds, as in nutrient agar, deoxyribo- nucleic acid might be synthesized via a degradation of glucose-6-phosphate to gluconate-6-phosphate, arabinose-5-phosphate, deoxyribose-5-phosphate, and deoxyribose-1,5-diphosphate, thence to nucleotides and nucleic acid. Such a degradative pathway has been suggested, at least in part, by Dickens ${ }^{3}$. If glucose is present in a synthetic medium, or if the cells are grown on nutrient agar without glucose, the deoxyribose in the deoxyribonucleic acid is probably synthesized by a condensation pathway involving two and three carbon compounds. In fact, Racker", and Marmur and Schlenk ${ }^{5}$ have shown that certain bacteria can form pentose by a condensation of two and three carbon compounds. Thus, if the virus in lysogenic strain $\mathrm{I} \cdot 0$ of Bac. megatherium parasitizes the condensation pathway to deoxyribose and not the degradation pathway, lysogenicity will be lost when glucose is added to nutrient agar at $p \mathrm{H} 7 \cdot 0$, and the degradation pathway is opened. If the glucose nutrient agar is at $p H \quad 8.0$, the virus with the help of the high $p H$ can prevent the host cell from utilizing either the degradation or condensation pathway, and growth is prevented. As expected, this inhibition occurs with glucose-6-phosphate but not with other intermediates of glycolysis.

Theoretically, it should be possible to isolate a strain of Bac. megatherium which will remain lysogenic in the presence of glucose in nutrient agar. Indeed, eight such strains have been isolated from nutrient agar containing $0.01 M$ glucose. These strains yield virus after repeated transfers on glucose nutrient agar and are resistant to infection with stock virus. However, these strains remain lysogenic on nutrient agar without glucose.

Proposed Pathways for the Synthesis of Deoxyribonucleic Acid by the Host Cells of Bacillus megatherium

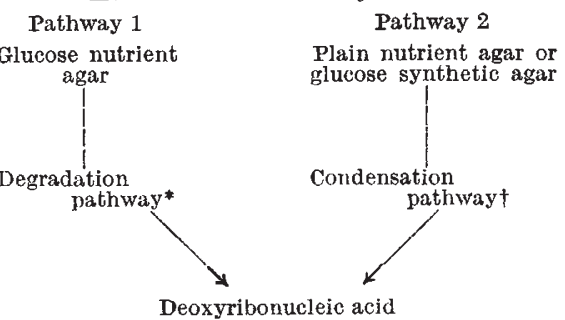

* Parasitized by virus of strains that remain lysogenic on glucose agar but not of strain $1 \cdot 0$.

+ Parasitized by virus of lysogenic strain 1.0 .

Thus it is suggested that different mechanisms may exist in the host cell of Bac. megatherium for the synthesis of deoxyribonucleic acid and that virus can parasitize one or more of these mechanisms (see chart). Thus, if the mechanism of synthesis of deoxyribonucleic acid that is utilized by the host can be parasitized by the virus, the virus is synthesized and the cells are lysogenic ; but if another pathway is made available, for example, when glucose is added to nutrient agar, the alternative pathway will be used and lysogenesis will be lost.

\section{H. L. EHRLICH}

S. G. KNIGHT*

Department of Agricultural Bacteriology,

University of Wisconsin, Madison, Wisconsin.

* Fulbright Iceturer in Microbiology, University of Edinburgh. ${ }^{1}$ Ehrlich, H. L., and Watson, D. W., J. Bact., 58, 627 (1949).

2 Kozloff, I. M., and Putnam, F. W., J. Biol. Chem.. 182, 229 (1950).

3 Dickens, F, and Glock, G. E., Nature, 168, 33 (1950).

- Racker, E., Fed. Proc., T, 180 (1948).

s Marmur, J., and Schlenk, F., Arch. Biochem., 31, 154 (1951). 